\title{
El periodismo en Baja California y la Revolución Mexicana
}

\section{The Journalism in Baja California and the Mexican Revolution}

\section{Ángel Manuel Ortiz Marín}

mortiz@uabc.edu.mx

https://orcid.org/0000-0002-1849-4649

Facultad de Ciencias Humanas

Universidad Autónoma de Baja California

México

\section{Resumen}

El autor documenta en este artículo la situación del periodismo en Baja California, México, antes, durante y después del periodo de la revolución mexicana.

Mediante la recopilación y la interpretación de diversas fuentes documentales, el trabajo da cuenta del contexto sociopolítico en el que se produjo el nacimiento del diarismo regional para luego detallar y describir las características y el rol desempeñado por los diferentes y numerosos periódicos que, entre 1900 y 1920, fueron publicados en las ciudades y en los poblados de esta zona fronteriza.

Palabras clave

periodismo, Baja California, Revolución Mexicana, periódicos

\section{Abstract}

The author documents in this article the situation of journalism in Baja California, Mexico, before, during and after the period of the mexican revolution. Through the compilation and interpretation of various documentary sources, the work gives an account of the social-political context in which the birth of regional diarism took place and then details and describes the characteristics and the role played by the different and numerous newspapers that, between 1900 and 1922 , they were published in the cities and tows of this border area.

Keywords

journalism, Baja California, Mexican Revolution, newspapers 


\title{
El periodismo en Baja California
}

\section{y la Revolución Mexicana}

\author{
Por Ángel Manuel Ortiz Marín
}

La tarea de construir un relato sobre acontecimientos pasados remite a concebir a la historia como la ciencia indispensable para elaborar una narrativa de tales sucesos a partir de las fuentes disponibles, y proceder, en consecuencia, a su interpretación hermenéutica a fin de acceder a un conocimiento científico cercano a la realidad, señala Enrique Moradiellos (1998).

De ahí que sea la historiografía, tal como indica Eduardo Torres Cuevas (2002), la herramienta pertinente para este proceso, particularmente, el enfoque que permite vincular la reconstrucción de los hechos pensados como procesos que corresponden a las realidades de la sociedad en su momento histórico. El estudio sobre los medios y su teorización es un componente más que contribuye a explicar el papel de la prensa en un escenario sociopolítico y cultural como el que se expone.

Por tal razón, y en el interés de ampliar el conocimiento sobre la prensa a nivel regional, este texto aborda los inicios de los periódicos en Baja California a principios del siglo XX. Para ello, refiere a los antecedentes de los diarios en México en ese periodo como contexto nacional, para después ubicar la realidad periodística en la Baja California de esa época, la cual en ese momento aún era un distrito y no una entidad federativa.

Los hombres pioneros del periodismo y los primeros periódicos de la época cobran significado por diversas razones. En relación con el surgimiento de los medios de comunicación, fueron la aparición y el desarrollo de la fotografía y el cine -como formas culturales de arte, primero; de entretenimiento, después; y, finalmente, de informaciónlos que representan los inicios de las formas de comunicación dirigidas hacia públicos cada vez más interesados en los aconteceres.

En cuanto a la política en México, fueron el porfiriato y sus expresiones disímbolas en cuanto a los avances de la ciencia, el pensamiento positivista, la inversión extranjera, el surgimiento de la cultura refinada con tintes afrancesados y el desarrollo ferroviario 
como puntal del progreso material, los rasgos más destacados de dicho periodo. Y, en contraposición, el cacicazgo, la pobreza y la miseria del campesinado, que en su conjunto representaron la fase ominosa del régimen porfirista, además de una etapa de dictadura, que duró desde 1876 hasta 1911 como consecuencia del triunfo de la revolución mexicana.

En esencia, una época de fuertes contrastes, en los cuales el periodismo nacional y el bajacaliforniano, en menor medida, jugaron un importante papel al relatar el acontecer cotidiano, a veces a contracorriente y con el riesgo de la censura, el cierre de los diarios o el encarcelamiento y la desaparición de aquellos periodistas que osaron describir una realidad diferente a la versión oficial del gobierno.

El texto se inicia con una exposición del enfoque teórico y la metodología utilizada; se contextualiza, luego, el surgimiento de los primeros medios impresos en México y en algunas ciudades de provincia. A continuación, se documenta el panorama social, económico y político de Baja California a fines del siglo XIX y principios del siglo XX, para describir, posteriormente, el surgimiento embrionario de los diarios y las características del periodismo de esa época, que sentó las bases del que se practica en la actualidad en Baja California. Se concluye con algunas reflexiones que se comparten producto del trabajo historiográfico realizado sobre la prensa bajacaliforniana.

\section{Planteamiento teórico-metodológico}

En el caso de México, reflexionar sobre la prensa como campo de estudio es relevante para dimensionar su importancia en el relato de los hechos más significativos para la historia del país. Pero no solo de los grandes relatos, sino también de la cotidianeidad de quienes, como habitantes de una nación, de una provincia o de una ciudad, en su conjunto, conforman el mosaico del mundo de vida de sus ciudadanos.

Para documentar el tema del periodismo de Baja California antes, durante y después del periodo de la revolución mexicana, se acudió a la historiografía, cuya metodología principal, como recomienda Celia Palacio Montiel (2006), indica la recopilación y la interpretación de las fuentes documentales; en este caso, los libros sobre Baja California y el nacimiento y el desarrollo de sus principales ciudades a finales del siglo XIX y principios del XX. En este sentido, los distintos autores revisados, además de dar cuenta del nacimiento del diarismo regional y sus periódicos, refieren los acontecimientos 
sociopolíticos y económicos que contextualizan su aparición y caracterizan a quiénes, como directores, asumieron la aventura, en esa época con mayor razón, de publicar un diario. De ahí que la pretensión sea vincular el surgimiento de los diarios bajacalifornianos tanto con los hechos políticos y con los personajes más significativos para la época como con aquellos sucesos sociales, culturales y económicos relevantes para la sociedad de la provincia.

En cuanto a la perspectiva comunicacional, el estudio le tributa a Manuel Martín Serrano (1985) su perspectiva de la prensa como una mediación social, ya que el Estado y los medios de comunicación masiva (MCM) mantienen una relación orgánica, además de una interdependencia estructural, para incidir en los componentes sociopolíticos y económicos de una determinada época y país. De ahí que los MCM, al plasmar la vida activa de la sociedad en sus páginas, se convierten en una fuente documental importante para el análisis de determinados hechos sociohistóricos.

Martín Serrano (1985) refiere que los medios operan, según el conflicto por informar, desde la mediación cognitiva, pues al documentar el nuevo acontecer que rompe con la cotidianeidad, y que compromete la normalidad social, tienden a ajustar el relato del hecho a las normas y a los valores socialmente legitimados como ocurre con sucesos como movimientos revolucionarios, campañas electorales o tragedias.

Es necesario reconocer que, desafortunadamente, no fue posible acceder a los impresos originales de los periódicos bajacalifornianos que se citan en este texto, dado que, en algunos casos, su vida fue efímera (uno o dos ejemplares); y, en otros, pertenecen a colecciones privadas y no están disponibles en hemeroteca alguna. Frente a esto, se decidió acudir a los textos de autores bajacalifornianos que, al narrar pasajes de la historia de esa época, mencionan los diarios y sus características principales, aunque con escasas ilustraciones.

\section{Antecedentes del periodismo en México a fines del siglo XIX}

Como diversos acontecimientos significativos de carácter cultural, económico y político, en México el periodismo germinó en el siglo XVIII, a partir de la publicación, en 1722, de La Gaceta de México y Noticias de la Nueva España. Considerada la primera en su género en América Latina, según señala Manuel Suárez Rivera (2015), contaba con una 
edición mensual dedicada a informar sobre los sucesos relevantes de la capital y los aconteceres de las provincias de la Nueva España, siendo su primer editor Juan Ignacio Castorena y Urzúa. Si bien fue la primera en su tipo, su duración fue efímera por razones económicas.

En ese siglo, también hubo otras publicaciones periodísticas que tuvieron diversos intereses, aunque no siempre de carácter periodístico sino más bien de tipo cultural o llamadas científicas. Entre ellas, hubo dos importantes publicaciones, según indica Xavier Tavera Alfaro, citado por Iñigo Fernández (2010), la segunda Gaceta de México, que nació en 1728 editada por el sacerdote Juan Francisco de Sahagún, cuyos contenidos temáticos fueron similares a la anterior, y, para 1772, El Mercurio Volante, primera publicación periódica de corte científico que editó el médico y físico José Ignacio de Bartoloche.

Daniel Sanabria Barrios (2011) indica que previo al proceso de independencia surgieron diferentes publicaciones. Para la ciudad de México, señala el caso de El Pensador Mexicano (1812-1814), de José Joaquín Fernández de Lizardi; para otras ciudades del interior, menciona El Telégrafo de Guadalajara (1811-1813) y el Despertador Americano (1810-1811), de Severo Maldonado; para Oaxaca, el Correo Americano del Sur y, para Michoacán, El Sud, ambos datados en 1813. Especial significancia mereció El Diario de México (1805-1817), editado por Carlos María Bustamante en la ciudad de México, el cual se constituyó en esa época, según refiere Esther Martínez Luna (2009), en el espacio preferido para la expresión de la prolífica literatura y cultura mexicana.

En el periodo posterior a la independencia, según relata Fernández (2010), se pueden señalar las siguientes publicaciones: La Gaceta Imperial de México (1821); El Farol en Puebla (1821); La Avispa de Chilpancingo (1821-1822); El Seminario Político y Literario, por José María Luis Mora (1820-1821) y, por el mismo editor, El Observador de la República Mexicana (1827-1828) y otros más, algunos de efímera duración y otros con mayor presencia, tanto en la capital del país como en las capitales de los Estados de Puebla, Veracruz, Jalisco, Michoacán y Yucatán.

Mención especial merecen El Siglo XIX y El Monitor Republicano. El primero fue fundado por Ignacio Cumplido, Mariano Otero y Juan Bautista, en 1841, y permaneció vigente hasta 1867; el segundo, nació en 1844, editado por Vicente García Torres. Nora PérezRayón (2014) señala sobre el primero que «fue un instrumento de lucha en una época de guerras» (p. 4) y, del segundo, que tuvo mayor preocupación por los problemas sociales de la época, identificándose con las clases obrera y campesina. 
Asimismo, en este siglo surgió la prensa obrera de carácter liberal, cuyo ejemplo fueron El Ahuizote (1874-1876) o El Hijo del Trabajo (1876-1884), como indica Pérez-Rayón (2014). Otro ejemplo de este tipo fue el periódico El Socialista, cuyo primer ejemplar se publicó en 1880, relacionado con el Círculo de Trabajadores de México que, según Luis Reed Torres y María Ruiz Castañeda (1998), tuvo por función informar sobre las actividades de dicha organización y sus eventos, así como ejercer una crítica al sector patronal. Por su parte, Gabriel Landa (2000) indica que también existieron medios dirigidos a la clase obrera, pero de carácter ideológico, como los diarios La Internacional (1878) y La Revolución Social (1879-1880), entre otros periódicos.

Por supuesto, existieron en este fin de siglo diarios de carácter religioso, cultural, científico-técnico, de contenido femenino, infantil, humorístico y, claro está, de corte político, dado que dicho periodo se caracterizó por las constantes revueltas políticas y armadas, además del surgimiento de varios partidos políticos, tanto a nivel nacional como regional, y de grupos de poder político-económico que aspiraron a conformar una opinión pública entre los simpatizantes afines a sus intereses.

El fin del siglo XIX se caracterizó por el rol que tuvieron los diarios de esta etapa histórica, los cuales, según Palacio Montiel (2006), fueron actores importantes «para la constitución de la esfera pública y literaria en México» (p. 14). En pleno porfiriato, la prensa tuvo por característica la práctica de un periodismo opositor y combativo, con plumas forjadas, ya fuera en la lucha armada o en la ideológica y, por supuesto, con el principal objetivo de enjuiciar de forma crítica al gobierno; es decir, un periodismo de combate, como refieren Reed Torres y Ruiz Castañeda (1998). Un ejemplo es el diario Regeneración, editado en 1900 por los hermanos Flores Magón, en la ciudad de México, el cual se convirtió en el órgano oficial del Partido Liberal Mexicano. Armando Bartra (1980) señala que este diario, dirigido fundamentalmente a la clase obrera y que logró tener tirajes de 30 mil ejemplares, fue un fiero opositor del régimen porfirista

Otros diarios, también de carácter opositor al régimen porfirista, según indica Karin Bohmann (1989) fueron: El Anti-Reeleccionista, de José Vasconcelos y Moisés Sanz; El Constitucionalista, de Rafael Martínez; México Nuevo, El Partido Democrático y distintos diarios de menor presencia, que formaron parte de un sector del periodismo que enjuició continuamente al presidente Porfirio Díaz por sus actos de despotismo, de abuso de autoridad y por negarse a dejar la silla presidencial. 
En ese periodo surgieron, en provincia, tres importantes periódicos que a la fecha aún se publican. Miguel López Domínguez (2007) cita a Aurora Cano Andaluz quien refiere a El Informador de Guadalajara (1917), El Porvenir de Monterrey (1919) y El Dictamen del Puerto de Veracruz (1912), medios que han forjado a lo largo de los años una trayectoria periodística singular y han formado generaciones de periodistas hasta la fecha.

Para dimensionar las condiciones educativas en las cuales se encontraban los diarios de la época en relación con los posibles lectores -dado que los periódicos eran considerados como artículos de lujo por el escaso poder adquisitivo de la población en general-, hay que tomar en cuenta que el problema del analfabetismo era sumamente grave, pues «apenas casi un 30\% de la población mayor de 10 años sabía leer en 1910» (Bohmann, 1989, p. 68). De allí que los lectores habituales de la prensa de esa época fueran las clases medias y altas, y los propios periodistas, además de los políticos, comerciantes, maestros, intelectuales y estudiantes adinerados, pues, en general, los periódicos se editaban en las grandes ciudades. Lo cual es confirmado por Florence Toussaint (1989), quien indica que a finales del siglo XIX y principios del XX hubo 2.579 periódicos; la mayor parte, poco más de dos mil, en las provincias, y 576 en la capital del país.

Estos son algunos de los rasgos más sobresalientes del periodismo en dicha época de la historia en México, en gran medida un periodismo de corte literario, político y científico. Lo significativo de estos hechos es que dicha prensa forjó las bases de lo que después se puede considerar el periodismo en México del siglo XX. Particularmente, por su proceso de desarrollo tecnológico y por la profesionalización de la actividad, así como por el surgimiento de los grandes diarios que, si bien se asentaron en la capital del país, contaron con un prestigio que les permitió trascender a la provincia e, incluso, en el caso de algunos de ellos al extranjero.

\section{El periodismo en Baja California entre 1900 y 1920}

\section{El contexto bajacaliforniano a fines del siglo XIX}

Previo a abordar el desarrollo del periodismo en esa etapa, es pertinente presentar un esbozo del contexto socioeconómico y político de Baja California, con el interés de ampliar la mirada sobre los diversos aconteceres ocurridos en la provincia a finales del siglo XIX. 
Habrá que recordar que a mediados del siglo XIX, por decreto presidencial de 1849, según lo señala José Lara Chavarría (2003), la península bajacaliforniana quedó comprendida en dos entidades: el Partido Sur y el Partido Norte. En un principio, la cabecera de este último fue el poblado de Santo Tomás y, posteriormente, como afirma José Álvarez (1999), la capital se trasladó al poblado de Real del Castillo. Para 1882, el Presidente decretó como capital de esta nueva territorialidad al puerto de Ensenada de Todos los Santos. Y, en 1887, por decreto expedido por el Congreso de la Unión, esta parte de la península fue nombrada oficialmente como Distrito Norte de la Baja California (Martínez, 2005).

En esa época, las labores productivas más comunes en el Distrito Norte, indica Modesto Rolland (1993), fueron el comercio, la ganadería y una incipiente agricultura. En especial, en el puerto de Ensenada, las actividades principales consistieron en la pesca y el comercio; esto último, en virtud de la fuerte inversión en el desarrollo urbano de Ensenada por la Compañía Internacional de México.

El poblado de Tijuana, fundado en 1889 -cuyo primer nombre fue Pueblo de Zaragoza-, colindante con el estado de California, Estados Unidos de América (EUA), fue la aduana entre ambos lados de la frontera binacional. Su principal actividad fue el comercio, además de los famosos baños de aguas termales de Agua-Caliente (Aguirre Bernal, 1990).

Mexicali -en la actualidad, capital del Estado- era, en ese entonces, una pequeña población. Fundada en 1903, señala Adalberto Walter Meade (1988), el levantamiento de un censo al año siguiente de su fundación registró 397 habitantes. La principal actividad de dicho poblado, en esa primera década del siglo XX, fue la agricultura; en particular, la siembra del algodón, en tierras que, en su mayoría, estuvieron en manos de inversores extranjeros como la Colorado River Land and Company. Este auge algodonero generó en los siguientes años el desarrollo de Mexicali y el crecimiento de su población, según lo señalado por Aidé Grijalva Larrañaga (1988).

Un reflejo de la fuerte presencia extranjera en la región la ofrece Pablo Martínez (2005), al señalar que «Ensenada tenía al 31 de enero de 1888, una población de 1.375 almas, de los cuales el 28 por ciento era mexicana» (p. 542). La mayoría de esta población eran personas dedicadas a la minería y al comercio. Por las condiciones fronterizas de la entidad, hay dos aspectos que destacan tanto David Piñera Ramírez (1991) como Rolland (1993) y Martínez (2005). Por una parte, y ya desde sus orígenes, la actividad minera y, posteriormente, la comercial, dada su cercanía con los Estados Unidos, lo que permitió el 
tránsito de productos y de personas como sucede hasta la actualidad. Por otra parte, el aislamiento del centro del país, que dificultó la continuidad de la comunicación de casi cualquier tipo. De ahí que su constitución como entidad federativa no ocurriera hasta la mitad del siglo XX, lo que reforzó su notoria dependencia de la federación, tanto en lo político como en lo económico.

\section{Los inicios del diarismo en Baja California}

El primer antecedente que se tiene de un diario en Baja California se encuentra en la población de Real del Castillo. Se trata de El Fronterizo, que se publicó en 1872 (Reed Torres y Ruiz Castañeda, 1998). Esta fecha de inicio, empero, no coincide con el dato que ofrece Gabriel Trujillo Muñoz (200o), quien, por su parte, cita a Armando L. Lelevier, el cual señala: «Eliseo Schieroni, de nacionalidad italiana, fundó el primer periódico particularmente con el nombre de El Fronterizo en los primeros días de marzo de 1873» (p. 33). Complementando dicha información, Lara Chavarría (2003) indica que este diario fue «fundado por Manuel Clemente Rojo y Eliseo Schieroni y que estuvo en circulación durante dos años» (p. 252).

En 1873, se editó Diario Oficial, el primer periódico oficial del gobierno publicado por Manuel Clemente Rojo, quien, para ese entonces, ocupaba la subprefectura del Partido Norte de Baja California. Este periódico fue refundado en 1888 con la denominación de Periódico Oficial y se convirtió en el órgano oficial del gobierno del ahora Distrito Norte, siendo su primer director Pedro Rendón (Trujillo Muñoz, 2000).

La razón de que el poblado de Real del Castillo fuera la cuna del periodismo bajacaliforniano fue el desarrollo de la explotación minera, que repercutió en su crecimiento poblacional y llevó a que sea nombrado cabecera del Partido Norte. De allí que cuando el auge de la minería decayó, la capital fuera trasladada a Ensenada, donde se asentó entre 1882 y 1915, según indica Carlos Lazcano (2011).

En 1886, de acuerdo a lo señalado por Piñera Ramírez (1991), surgió en Ensenada el semanario La Voz de la Frontera de la Baja California, auspiciado por la Compañía Internacional de México (propiedad de inversionistas de nacionalidad estadounidense). «Este periódico bilingüe (español e inglés) era un órgano mediante el cual la compañía hacía promoción a sus inversiones, incluyendo obviamente el desarrollo urbano de Ensenada» (Piñera Ramírez, p. 151). 
Otro diario que también nació en Ensenada fue The Lower Californian, en 1887, apoyado por la Compañía Editorial de Baja California. Rogelio Casas Sánchez (2006) indica que este periódico fue el primero en usar una prensa mecánica para imprimir sus ejemplares. Orientado por el objetivo de promover la colonización de la parte norte de la península, este medio destacaba el desarrollo de la región y, en particular, la construcción de un ferrocarril peninsular y una posible universidad.

En El Álamo, poblado bajacaliforniano que creció gracias a la fiebre del oro, surgió en 1889 el diario «El Álamo Nugget, o sea, La chispa de oro de El Álamo» (Martínez, 2005, p. 545).

Previo al periodo revolucionario, surgieron varios diarios de duración efímera como El Correo del Norte (1887-1903), El Progresista (1903-1904) y El Demócrata del Norte (1911), entre otros (Álvarez, 1999).

\section{La etapa revolucionaria en Baja California}

A diferencia de otras regiones fronterizas del norte de México, en Baja California la revolución mexicana no se significó por las grandes batallas o por el movimiento de contingentes armados de los ejércitos de los bandos en disputa, como sucedió en las provincias de Sonora, Chihuahua, Coahuila, Tamaulipas o Nuevo León. Si bien los principales caudillos revolucionarios tuvieron presente esta frontera por su inmediatez con California, EUA, y por el flujo de armas hacia los ejércitos revolucionarios, lo cierto es que no tuvo el impacto militar de otras regiones fronterizas.

Martínez (2005) indica que el movimiento armado impulsado por el Partido Liberal Mexicano, fundado por los hermanos Flores Magón, tuvo una fuerte impronta en California, EUA, lo cual ocurrió también en el Distrito Norte de la Baja California; sin embargo, «en Baja California no hubo alzamiento maderista» (Martínez, 2005, p. 562).

Es de reconocer que Francisco I. Madero -político opositor a Díaz y quien finalmente encabezó la primera etapa de la revolución mexicana- tuvo vínculos con los hermanos Flores Magón, quienes establecieron su cuartel en Los Ángeles tras ser perseguidos por Díaz debido a su identificación con el movimiento anti reeleccionista encabezado por Madero; aunque el radicalismo floresmagonista difirió de la estrategia maderista, según Linda Hall y Don Coerver (1995). 
En los primeros años del siglo XX hubo varios enfrentamientos entre fuerzas armadas del Partido Liberal Mexicano y el ejército federal con la intención de posicionarse en la Baja California y, en particular, en las ciudades de Tijuana y de Mexicali. Martínez (2005) señala que este último, «en ese entonces, (1911) contaba con una población de 400 habitantes» (p. 563); y agrega que en dicha población «fue obstaculizada la lucha armada tanto por tropas mexicanas como del lado de Calexico, EUA, por destacamentos del ejército norteamericano que impidieron el cruce de armas para los rebeldes del Partido Liberal Mexicano» (p. 564).

De este suceso da cuenta Celso Aguirre Bernal (1990), quien señala que en enero de 1911 un pequeño grupo armado magonista tomó por asalto los principales edificios de Mexicali y ocupó la plaza. Igual suceso refiere que tuvo lugar en Tijuana, también tomada por los rebeldes magonistas. Sin embargo, ambas plazas fueron liberadas tiempo después por el ejército federal y con ello, en ese mismo año, concluyó el movimiento revolucionario en la Baja California.

Este hecho armado ha sido objeto de diversas interpretaciones históricas; incluso se llegó a suponer que Ricardo Flores Magón pretendió separar la Baja California de la nación mexicana y fue acusado de filibustero por esa pretendida acción. Sin embargo, Lowell Blaisdell (1993), en su obra La Revolución del desierto. Baja California, 1911, se encarga de desmentir dicha afirmación y destaca que las fuerzas magonistas, en su afán por impulsar la caída del porfirismo y por separarse ideológicamente del maderismo, tomaron la iniciativa de capturar tanto Tijuana como Mexicali, dando inicio a la campaña liberal en México. Con esta tesis coinciden varios autores, como Martínez (2005) y Mario Gill (1988), entre otros.

Otro aspecto manifiesto en esta etapa revolucionaria fue la migración de connacionales a los Estados Unidos de América, dada la vecindad con California. Hall y Coerver (1995) indican que en el periodo de 1911 a 1920 «el flujo de inmigrantes mexicanos por esa región fronteriza llegó a 16.864 personas» (p. 205). Si bien no era una cantidad elevada (8,1 por ciento del total de inmigrantes legales) en comparación con los migrantes que cruzaron hacia Texas (71,1 por ciento), Arizona (12,4 por ciento) u otros Estados de la Unión Americana (82,3 por ciento), la motivación de este flujo migratorio fue ir a trabajar en los campos agrícolas de California, actividad que a la fecha aún se desarrolla de manera extensiva, tanto por migrantes legales como ilegales. 
El movimiento revolucionario de 1910 fue ampliamente documentado por la prensa de la época a nivel nacional, pero no así por la de Baja California, donde la lucha armada fue de escasa presencia, excepto por los sucesos de 1911 protagonizados por las fuerzas magonistas, a los cuales los diarios bajacalifornianos le dedicaron las ediciones más sobresalientes. Fuera de estos hechos, las noticias comúnmente referían a los cambios de dirigencia de quienes gobernaban la parte norte de la península, al movimiento comercial, las fiestas patrias, las actividades culturales y sociales, y los sucesos internacionales más significativos. Es decir, la vida cotidiana de la sociedad de Baja California y, por supuesto, de las clases adineradas de preferencia.

Si bien el periodismo de esos primeros años y de la etapa revolucionaria no puede definirse en términos de géneros periodísticos como en la actualidad, resulta notorio que en sus diversas páginas y tipos de información se privilegiaron las notas periodísticas relacionadas con los personajes poderosos, ya fueran políticos, el gobernante del Distrito o los incipientes grupos económicos de la región.

Pese a ello, y a las difíciles condiciones que enfrentaba el surgimiento de un diario, así como el ejercicio del periodismo en esa etapa de la historia de México y, en particular, en Baja California, tanto en Tijuana como en Ensenada y en Mexicali surgieron varios periódicos. En este sentido, sobresale el puerto de Ensenada, por la actividad social, cultural, política y por el periodismo de esos años. Señala Trujillo Muñoz (200o) que «el 18 de abril de 1903 se publica el primer número de El Fronterizo, a cargo de José María Obando, y El Progresista, también en ese mismo año, bajo la dirección de Carlos R. Ptanik» (p. 38). Según el autor, este último diario sentó las bases de lo que sería el periodismo bajacaliforniano, tanto por su formato como por su estilo y por su cuidado editorial.

Valdemar Jiménez Solís (2006) indica que en 1908 se publicó en el puerto de Ensenada el diario La Voz de la Frontera -distinto del anterior La Voz de la Frontera de la Baja California, de 1886-, dirigido por el profesor José María García. Este autor también indica que en el puerto fueron publicados otros dos diarios, ambos en 1911, uno fue el semanario El Demócrata del Norte y, otro, el periódico quincenal Pluma y Alma, bajo la dirección de Manuel Sánchez Hernández. Justamente, de El Demócrata del Norte Trujillo Muñoz (200o) señala que fue un semanario auspiciado por el Club Democrático de Ensenada, grupo civil del cual fue vocero, siendo su redactor principal Enrique Rivera. Este diario, 
que tuvo por finalidad «manifestar apoyo político a la candidatura de Madero» (p. 64), se convirtió en un medio independiente y abierto a las diversas expresiones de la vida democrática de la sociedad bajacaliforniana.

Mención especial merece la referencia que hizo el diario Regeneración, impreso en Los Ángeles, California, a los sucesos armados protagonizados por las fuerzas magonistas en las tomas de las plazas de Tijuana y de Mexicali, en 1911. Roselia Bonifaz de Hernández (1983) señala que dicho diario, vocero del Partido Liberal Mexicano, alentó la toma de estas ciudades y festejó cada una de las victorias de las fuerzas magonistas, animando a la colonización de Baja California para «dar vida a esta porción de México y poner en práctica los ideales redentores del Partido Liberal Mexicano» (p. 373).

Trujillo Muñoz (2000) narra que en plena etapa revolucionaria, y con motivo de la caída de Madero y de la toma del poder por Victoriano Huerta, diferentes gobernadores se sucedieron en el Distrito Norte de la Baja California y que fueron las páginas de los diarios El Demócrata del Norte, La Voz de la Frontera y El Periódico Oficial, los tres de Ensenada, los espacios de debate político. Las plumas de sus colaboradores y sus redactores dieron cuenta, cada uno desde su posición política, de los trágicos sucesos relacionados con el asesinado de Madero y, en el ámbito local, del juego político de quienes gobernaron la Baja California.

En esta etapa del movimiento revolucionario, Pedro Pérez y Ramírez (1983) indica que surgieron varios diarios en Mexicali; entre ellos, el Noticioso del Distrito, en 1915, impreso en la vecina ciudad de Calexico, California, y dirigido por Gustavo Becerra, y, un año después, en 1916, Tricolor, dirigido por Juan Galarza.

Trujillo Muñoz (2000), citando a Lelevier, indica que, en 1917, surgió el diario La Crónica, que solo tuvo dos ediciones en ese año. También refiriendo a Lelevier, Pérez y Ramírez (1983) señala que en 1917 se editó Vanguardia, «el primer periódico serio con arraigo en el periodismo mexicalense» (p. 416), cuya dirección estuvo a cargo de Ignacio Roel. De este diario, el primero en la frontera bajacaliforniana que usó la prensa plana y el linotipo, Trujillo Muñoz (200o) expresa: «Es la prensa del Coronel Cantú frente a sus adversarios. La mayoría de estos ensenadenses, resentidos por el traslado de la capital, utilizan El Demócrata del Norte, como ariete para fustigar la administración cantuísta» (p. 74).

Un aspecto importante que involucró en esa época la fuerte relación entre Estados Unidos y México fue la declaración, en 1919, de la Ley Volsted, también llamada Ley Seca, que prohibía en EUA la venta, la importación y la fabricación de bebidas alcohólicas. 
Esto provocó que las ciudades fronterizas fueran convertidas en sitios de diversión y de entretenimiento para los ciudadanos norteamericanos, lo que estimuló en el Distrito Norte, sobre todo en Tijuana, un extraordinario desarrollo comercial y demográfico, además del surgimiento de los casinos de juego, el esplendor del renovado hipódromo, múltiples bares y cantinas -La Ballena, con una barra de 170 metros, se anunciaba como la más grande del mundo- y, en consecuencia, el crecimiento de la delincuencia, la prostitución y la drogadicción (Walter Meade, 1983; Pérez y Ramírez, 1983). De allí que, por ese entonces, las páginas de los diarios dieran cuenta frecuente $y$ abundantemente de las fiestas, las reuniones sociales y las actividades comerciales y políticas que se estimularon gracias al desarrollo económico.

En 1920, tras la llegada del general Álvaro Obregón a la presidencia de México, el coronel Esteban Cantú, para entonces gobernador del Distrito, abandonó la Baja California y el diario Vanguardia desapareció del escenario periodístico. Al finalizar el periodo revolucionario, indica Jiménez Solís (2006), surgió el diario El Regional, fundado por José S. Castillo. También ese año se publicó en Mexicali El Monitor, dirigido por Ricardo Cobarrubias. Trujillo Muñoz (200o) señala que Cobarrubias tuvo por política editorial evitar comprometerse con los líderes políticos locales; sin embargo, sí se manifestó más afín al gobierno obregonista, al grado de publicar señalamientos en contra de los todavía simpatizantes del anterior gobernador, Esteban Cantú.

Dada la cercanía de las ciudades de Tijuana y de Mexicali con los Estados Unidos de América, no se puede olvidar, como marca Trujillo Muñoz (200o), la relación con los medios de California, en virtud de la importancia que por esos años tuvieron tanto para la vida periodística como política, comercial y social de la región. Estos diarios fueron: por San Diego, The San Diego Sun y The San Diego Union, y por Calexico, el Calexico Daily Chronicle. Al respecto, señala este autor que «un buen porcentaje de los periódicos bajacalifornianos fueron impresos en Calexico, Brawley o San Diego» (p. 98).

Entre 1920 y 1923 fueron nombrados diversos gobernadores del Distrito Norte, pero no fue hasta la llegada de Abelardo L. Rodríguez, quien permaneció en el cargo desde noviembre de 1923 hasta 1929, cuando hubo mayor estabilidad político-administrativa en la región (Trujillo Muñoz, 200o).

Conrado Acevedo, David Piñera Ramírez y Jesús Ortiz (1983) refieren que no fue hasta 1925 que surgió el primer diario en la población de Tijuana, llamado La Voz de Tijuana. Lo tardío de la publicación de un periódico en esta ciudad fronteriza se debió a la 
presencia entre los tijuanenses de diarios californianos como El Heraldo de México y el Hispano Americano, ambos editados en Los Ángeles e impresos en español. Posteriormente, en 1927, se publicaron en Tijuana El Nacional y el semanario Labor.

Para esta etapa pos revolucionaria, Trujillo Muñoz (2000), citando a Lelevier, señala la presencia de varios diarios bajacalifornianos. A los ya referidos, se agregan los siguientes periódicos y sus directores: Boletín Municipal de Mexicali (1921); El Combate (1923), José Peredo; El Monitor Ilustrado, Ángel Saldívar; Mercurio, Juan Hernández; El Peninsular (1925), Eliseo Tavera; The Rounder (1923), Billy Silver; Momo (1923), Francisco Bernal; El Centinela (1924), Vicente Tavares; El Malcriado (1924), Salvador Casillas; El Artículo 123 (1924), Heriberto Villarino; La Frontera (1924), José Guadalupe Herrera Carrillo; El Eco Del Distrito Norte (1925), Manuel Esperón; El Reporter (1925), Heriberto; Boletín Municipal (1925), Facundo Bernal; El Combate (1925), Ángel Saldívar.

En términos administrativos, el 31 de diciembre de 1928, durante el gobierno del general Abelardo Rodríguez -quien posteriormente fue presidente de México en el periodo 1932-1934-, Mexicali fue declarada capital del Distrito Norte. El 7 de febrero de 1929, durante el mandato del licenciado Carlos Trejo, cambió la denominación de Distrito y se convirtió en Territorio Norte de la Baja California. Para 1951, el entonces presidente Miguel Alemán publicó el decreto que cambió la condición de territorio a Estado, pero no fue hasta el 16 de enero de 1952 que se publicó en el Diario Oficial de la Federación la Constitución de Baja California; desde entonces, el Estado 29 de la República Mexicana (Álvarez, 1999).

\section{Reflexiones finales}

Miguel León Portilla (1998) refiere tres grandes acontecimientos ocurridos en los años revolucionarios y pos revolucionarios que dejaron una fuerte huella en la historia de Baja California durante el siglo XX. El autor menciona: «1) La revolución socialista dirigida por los Flores Magón [...]; 2) La expropiación de las tierras de propiedad extranjera en la península y, sobre todo, en el Valle de Mexicali [...]; 3) La formulación de la tesis -en términos de derecho internacional- en torno al carácter del Golfo de California» (p.512). 
El periodismo bajacaliforniano de esa etapa, como señala Jiménez Solís (2006), estuvo fuertemente influenciado por el poder político de los gobernantes de turno y padeció dos fenómenos que subsisten en la actualidad: las dadivas gubernamentales que se ofrecían a los periodistas, debido a sus bajos salarios; y la persecución, las amenazas, y hasta la muerte, producto de disentir con sus publicaciones de la versión oficial. Tal es el caso, refiere Pérez y Ramírez (1983), citado por Trujillo Muñoz (200o), de José Cayetano Zepeda, director de El Eco del Distrito Norte, y de José Esperón, responsable de El Monitor, quienes fueron golpeados por personal de la guardia del gobernador Abelardo Rodríguez, en virtud de las críticas a su administración.

La importancia de la prensa a finales del siglo XIX y a principios del XX fue fundamental para la libertad de expresión de las ideas de esa época. Los diarios se convirtieron en el espacio de preferencia de los diferentes grupos políticos, pero también de lo cultural, lo social y lo económico, y plasmaron en sus páginas el devenir histórico del México de ese entonces, tal como refiere Martín Serrano (1985).

En el caso de Baja California, los periódicos que surgieron, los que permanecieron y, también, los que desafortunadamente desaparecieron, narraron la vida cotidiana de la emergente sociedad bajacaliforniana que en esos años se debatió entre las disputas de los grupos de poder locales, la creciente presencia de los intereses norteamericanos que buscaban dominar política y comercialmente la península, y la influencia política del gobierno federal, que designó a los gobernantes de turno sin tomar en consideración a la ciudadanía bajacaliforniana.

Pese a ello y, en gran medida, gracias a la persistente lucha de los periodistas por un periodismo con acento local, los diarios bajacalifornianos no solo se enfrentaron a las dificultades económicas para sobrevivir como medios de comunicación, sino también a la necesidad de asumir tareas múltiples. Como indica Pérez y Ramírez (1993), citado por Trujillo Muñoz (2000), el periodismo de esa época tuvo por características que «el periodista era reportero, director, administrador, corrector, y en ocasiones, barredor y formador, y demás funciones inherentes a la confección, financiamiento y circulación de un periódico» (p. 98).

Un elemento significativo de este texto es que la historia del periodismo de Baja California durante la revolución mexicana abordó los pormenores de estos acontecimientos desde la óptica de quien vive en dicha provincia y no desde el centro del país, como ha sucedido 
con muchos otros relatos históricos, en particular del periodismo regional que si bien refieren la historia de la prensa en México más bien dan cuenta de la prensa de la ciudad de México (Palacio Montiel, 2006).

Un siglo después, es preciso reconocer la ardua labor de los pioneros del periodismo en Baja California y su lucha por la libertad de expresión, agenda a la fecha vigente para el gremio periodístico en México y en muchas otras naciones.

\section{Referencias}

Acevedo, C., Piñera Ramírez, D. y Ortiz, J. (1983). Semblanza de Tijuana. 1915-1930. En D. Piñera Ramírez (Coord.), Panorama histórico de Baja California (pp. 389-395). Tijuana, México: Universidad Autónoma de Baja California. Aguirre Bernal, C. (1990). Compendio histórico-biográfico de Mexicali. Volumen II. Ciudad de México, México: Autoedición.

Álvarez, J. (1999). Diccionario Enciclopédico de Baja California. Ciudad de México, México: Instituto de Cultura de Baja California/Compañía Editora de Enciclopedias de México.

Bartra, A. (1980). Regeneración 1900-1918. La corriente más radical de la revolución mexicana de 1900 a través de su periódico de combate. Ciudad de México, México: Era.

Blaisdell, L. (1993). La Revolución del desierto. Baja California, 1911.

Ciudad de México, México: Universidad Autónoma de Baja California.

Bohmann, K. (1989). Medios de comunicación y sistemas informativos en México.

Ciudad de México, México: Alianza Editorial Mexicana/Consejo Nacional para la Cultura.

Bonifaz de Hernández, R. (1983). Los sucesos de 1911. En D. Piñera Ramírez (Coord.), Panorama Histórico de Baja California (pp. 363-376). Tijuana, México: Universidad Autónoma de Baja California.

Casas Sánchez, R. (mayo de 2006). La prensa escrita en los albores de Ensenada. Trabajo presentado en el XXV Simposio de Historia Regional. Ensenada, México: Asociación Cultural de Liberales de Ensenada. 
Fernández, I. (2010). Un recorrido por la prensa en México. De sus orígenes al año 1857. Documentación de las ciencias de la información, (33), 69-89.

Recuperado de https://revistas.ucm.es/index.php/DCIN/article/view/DCIN1010110069A

Gill, M. (1988). Flores Magón y los filibusteros. En M. Mathes (Comp.), Baja California. Tomo II (pp. 286-310). Ciudad de México, México: Instituto de Investigaciones Históricas DR. José María Luis Mora/SEP. Programa Cultural de las Fronteras/Gobierno del Estado de Baja California.

Grijalva Larrañaga, A. (1988). Colonización del Valle de Mexicali. En M. Mathes (Comp.), Baja California. Tomo II (pp. 234-248). Ciudad de México, México: Instituto de Investigaciones Históricas DR. José María Luis Mora/SEP. Programa Cultural de las Fronteras/Gobierno del Estado de Baja California.

Hall, L. y Coerver, D. (1995). Revolución en la frontera. Ciudad de México, México: Consejo Nacional para la Cultura y las Artes.

Jiménez Solís, V. (2006). Breves datos históricos del periodismo en Baja California. En A. Ortiz Marín (Coord.), Los medios de comunicación en Baja California (pp. 15-24). Mexicali, México: Universidad Autónoma de Baja California / Miguel Porrúa Editor.

Landa, G. (2000). Características temáticas de las publicaciones periódicas del siglo XIX, s/d.

Lara Chavarría, J. (2003). Manuel Clemente Rojo: pionero y eminente educador aventurero. En AA.VV., Memoria 2003. Duodécimo ciclo de conferencias (pp. 203-261). Ensenada, México: Seminario de Historia de Baja California, Gobierno del Estado de Baja California.

Lazcano, C. (6 marzo de 2011). Real del Castillo, la antigua capital. El Vigía. Recuperado de https://www.elvigia.net/general/2011/3/6/real-castillo-antiguacapital-38200.html

León Portilla, M. (1998). Baja California en la historia universal. En M. Mathes (Comp.), Baja California. Tomo II (pp. 503- 515). Ciudad de México, México: Instituto de Investigaciones Históricas DR. José María Luis Mora/SEP. Programa Cultural de las Fronteras/Gobierno del Estado de Baja California. 
López Domínguez, M. (2007). Rompecabezas de papel. La prensa y el periodismo desde las regiones de México. Siglos XIX y XX [Reseña]. Takwá, (11-12), 263-269. Recuperado de http://148.202.18.157/sitios/publicacionesite/pperiod/takwa/Takwa1112/miguel_lopez.pdf

Martínez, P. (2005). Historia de Baja California. Edición crítica y anotada.

Mexicali, México: Universidad Autónoma de Baja California.

Martínez Luna, E. (2009). A, B, C, Diario de México (1805-1812): un acercamiento. Alicante, España: Biblioteca Virtual Miguel de Cervantes.

Martín Serrano, M. (1985). Mediación cognitiva y estructural. En M. de Moragas (Ed.), Sociología de la comunicación de masas. I. Escuelas y autores (pp. 141-162). Barcelona, España: Gustavo Gili.

Moradiellos, E. (1998). El oficio del historiador. Madrid, España: Siglo XXI.

Palacio Montiel, C. (2006). La prensa como objeto de estudio. Panorama actual de las formas de hacer historia de la prensa en México. Comunicación y Sociedad, (5), 11-34. Recuperado de https://www.redalyc.org/articulo.oa?id=34600502

Pérez-Rayón, N. (2014). La prensa liberal en la segunda mitad del siglo XIX.

Ciudad de México, México: Universidad Latinoamericana. Recuperado de http://practicasprofesionales.ula.edu.mx/documentos/ULAONLINE/Licenciatura/ CPH403/Semana_2/CPH403_S2_E_Prensa_Liberal.pdf

Pérez y Ramírez, P. (1983). Panorama de Mexicali 1915-1930. En D. Piñera Ramírez (Coord.), Panorama histórico de Baja California (pp. 396-418). Tijuana, México: Universidad Autónoma de Baja California.

Piñera Ramírez, D. (1991). Los orígenes de Ensenada y la política nacional de colonización. Tijuana, México: Universidad Autónoma de Baja California, Gobierno del estado de Baja California, Grupo Cultural Septentrión.

Reed Torres, L. y Ruiz Castañeda, M. (1998). El periodismo en México. 500 años de historia. Ciudad de México, México: EDAMEX/Club Primera Plana. Recuperado de http://www.paginaspersonales.unam.mx/files/4813/Asignaturas/1417/Archivo2.2362.pdf Rolland, M. (1993). Informe sobre el Distrito Norte de la Baja California. Mexicali, México: Universidad Autónoma de Baja California. 
Sanabria Barrios, D. (2011). Periódicos de la época de Independencia en Patrimonio Cultural del Tecnológico de Monterrey. Recuperado de

http://eprints.rclis.org/16174/1/Periodicos.pdf

Suárez Rivera, M. (2015). El periodismo en construcción. Estrategias comerciales de la Gazeta de México. 1784-1785. Relaciones. Estudios de historia y sociedad, 36(143), 207-231. Recuperado de

http://www.scielo.org.mx/scielo.php?script=sci_arttext\&pid=So185$39292015000300207 \& \operatorname{lng}=$ es\&tlng=es

Torres Cuevas, E. (2002). Introducción. En Colectivo de autores, La historia y el oficio de historiador (pp. VII-XXVIII). La Habana, Cuba: Imagen contemporánea. Toussaint, F. (1989). Escenario de la prensa en el porfiriato. Ciudad de México, México: Fundación Manuel Buendía/Universidad de Colima.

Trujillo Muñoz, G. (200o). La canción del progreso. Vida y milagros del periodismo bajacaliforniano. Mexicali, México: Instituto de Arte y Cultura, XVI Ayuntamiento de Tijuana.

Walter Meade, A. (1983). Características generales de los regímenes de Cantú y Rodríguez. En D. Piñera Ramírez (Coord.), Panorama histórico de Baja California (pp. 389-395). Tijuana, México: Universidad Autónoma de Baja California.

Walter Meade, A. (1988). La fundación de Mexicali, 1903. En M. Mathes (Comp.), Baja California. Tomo II (pp. 248- 269). Ciudad de México, México: Instituto de Investigaciones Históricas Dr. José María Luis Mora/SEP. Programa Cultural de las Fronteras/Gobierno del Estado de Baja California. 